\title{
DISPOSIÇÃO DO NEMATÓIDE Bursaphelenchus cocophilus (COBB) BAUJARD, EM COQUEIROS PORTADORES DA DOENÇA ANEL-VERMELHO ${ }^{1}$
}

\author{
ADRIANA GUIMARÃES DUARTE², IVANILDO SOARES DE LIMA ${ }^{3}$, JOSEMILDO VERÇOSA DE ARAÚJO JÚNIOR ${ }^{4}$, \\ ALEXANDRE GUIMARÃES DUARTE ${ }^{5}$,ARIANE LOUDEMILA SILVADE ALBUQUERQUE ${ }^{6}$, MARCELO DE MENEZES CRUZ7 $^{7}$
}

RESUMO - Este trabalho teve o objetivo de conhecer como o nematóide Bursaphelenchus cocophilus tende a se distribuir no interior das plantas de coqueiros em estágios avançados da doença anel-vermelho. Nas amostras de raízes coletadas junto à base da estipe de coqueiros doentes, o número de nematóides foi consideravelmente maior que encontrado em raízes situadas entre um e três metros de distância da estipe. Observou-se que, à medida que se afasta da estipe, a possibilidade de encontrar nematóides na raiz é mínima, de forma que as chances de transmissão da doença, de uma planta para outra, através das raízes, devem ser muito pequenas. Na região do palmito, onde o tecido é mais tenro, é possível encontrar o nematóide tanto nas áreas avermelhadas quanto nas áreas aparentemente sadias. Nos tecidos do pecíolo, foram encontrados nematóides em pequena quantidade. Portanto, práticas profiláticas, visando à desinfecção do facão utilizado na colheita e despalma, devem ser realizadas com a finalidade de eliminar a transmissão da doença. Nenhuma das amostras obtidas dos tecidos da ráquis e dos folíolos estava contaminada. A população de nematóide é mais alta nos excrementos de túneis larvais das regiões apicais do coqueiro, o que confere maior chance de serem transportados para outras plantas, aderidos ao corpo do seu principal vetor, os adultos de Rhynchophorus palmarum.

Termos para indexação: Cocus nucifera, Nematoda, distribuição da população.

\section{DISPOSITION OF THE NEMATODE Bursaphelenchus cocophilus (COBB) BAUJARD, IN COCONUT PALM TREES WITH THE RED RING DISEASE}

\begin{abstract}
The aim of this work was to investigate how the nematode Bursaphelenchus cocophilus tends to distribute itself inside the coconut palm trees in advanced stages of the red ring disease. In the samples of the roots collected at the base of the stem of sick trees, the number of nematodes was considerably higher when compared to the number found in the roots situated between one and three meters away from the stem. It was observed that, as it stands back of the sick plant, the possibility to find nematodes in the root is remote, so that the chances of transmission of the disease, from one plant to another, by means of the roots are minimal. At the top part of the stem, where the tissue is softer, it is possible to find the nematode both in the discolored areas and in the adjacent tissues, apparently healthy. In the tissues of the petioles, nematodes were found in small amounts. Therefore, the practice of the scythe disinfections used in the harvesting and leaf pruning should be recommended with the purpose of decreasing the possibility of transmission of the disease. None of the obtained samples from tissues of the rachis and leaves were contaminated. The population of nematode is higher in the excrements of larval tunnels of the apical parts of the plant, which provide higher chances of being transported, from one plant to another, stuck on to the body of its main vector, the coconut palm weevil Rhynchophorus palmarum. Index terms: Cocus nucifera, Nematoda, distribution of the population.
\end{abstract}

\section{INTRODUÇÃO}

A cultura do coqueiro (Cocus nucifera $\mathrm{L}$.) é atacada por diversas doenças, que variam de importância em cada região. Segundo vários autores (Giblin-Davis, 1990; Warwick \& Leal, 2003), dentre as principais moléstias encontra-se o anel-vermelho, uma doença letal para o coqueiro e outras palmeiras de importância econômica, causada pelo nematóide Bursaphelenchus cocophilus (Cobb) Baujard.

O nematóide B. cocophilus depende de seus vetores biológicos para colonizar novos hospedeiros e difunde-se através dos adultos de Rhynchophorus palmarum L. (Coleoptera: Curculionidae), que os transportam das plantas atacadas para as sadias (Griffith \& Koshy, 1990; Sanchez \& Cerda, 1993; Giblin-

${ }^{1}$ (Trabalho 260-07). Recebido em;08-11-2007. Aceito para publicação em: 29-05-2008. Apoio Financeiro: BNB, FAPEAL, PROCOCO-AL.Parte da tese da primeira autora para obrtenção do título de Doutora em Ciências/Instituto de Química e Biotecnologia/ Universidade Federal de Alagoas.

${ }^{2}$ Professora Adjunto, Dra., Unidade Acadêmica Centro de Ciências Agrárias/ Universidade Federal de Alagoas, Campus Delza Gitaí, BR 104 Norte, Km 85. 57.100-000, Rio Largo-AL. agd@fapeal.br

${ }^{3}$ Professor Associado, Phd. Unidade Acadêmica Centro de Ciências Agrárias/Universidade Federal de Alagoas, Campus Delza Gitaí, BR 104 Norte, Km 85, 57.100-000, Rio Largo-AL, is1@fapeal.br

${ }^{4}$ Eng. Agrônomo, Mestrando em Produção Vegetal/Unidade Acadêmica Centro de Ciências Agrárias/Universidade Federal de Alagoas, Campus Delza Gitaí, BR 104 Norte, Km 85, 57.100-000, Rio Largo-AL, josemildo junior@hotmail.com

${ }^{5}$ Eng. Agrônomo. Mestrando em Produção Vegetal/Unidade Acadêmica Centro de Ciências Agrárias/Universidade Federal de Alagoas, Campus Delza Gitaí, BR 104 Norte, Km 85, 57.100-000, Rio Largo-AL, xandegd@yahoo.com.br

${ }^{6}$ Estudante do Curso de Zootecnia/Unidade Acadêmica Centro de Ciências Agrárias/Universidade Federal de Alagoas, Campus Delza Gitaí, BR 104 Norte, Km 85, 57.100-000, loude14@hotmail.com

${ }^{7}$ Professor Adjunto, MsC., Unidade Acadêmica Centro de Ciências Agrárias/Universidade Federal de Alagoas, Campus Delza Gitaí, BR 104 Norte, Km 85, 57.100-000, Rio Largo-AL, m.mcruz@uol.com.br 
Davis, 2001). A transmissão pode ainda ocorrer por contato direto entre a raiz de uma planta infectada e a de uma planta sadia (Araújo, 1990). O nematóide consegue migrar no solo de uma planta para a outra quando as condições de umidade são boas, principalmente em áreas de pouca drenagem (Chinchila, 1991; Tihohod, 1993). Os frutos, ou as mudas deles provenientes, caso tenham sido colhidos de pés afetados, podem também disseminar o nematóide (Griffith \& Koshy, 1990; Giblin-Davis, 2001). No entanto, palmeiras muito jovens, com idade inferior a dois anos, não desenvolvem a doença, mesmo quando inoculadas ainda no viveiro em mudas (Warwick \& Bezerra, 1992; Giblin-Davis, 2001). Franco (1964) relatou que a contaminação também pode ocorrer por meio das ferramentas de corte, como o facão no ato da colheita, ou pelo corte de raízes durante as operações de preparo do solo.

Thurston (1984) e Brathfwaite \& Siddiqi (1975) relataram que os coqueiros infectados por B. cocophilus levam de 23 a 28 dias para manifestar os primeiros sintomas da doença, e de 3 a 4 meses para morrerem. Blair (1970) e Giblin-Davis (1990) observaram que, em estado natural, a infestação inicia-se nos entrenós da coroa do coqueiro, onde os tecidos são mais tenros e alcançam desenvolvimento máximo entre 5 e 7 anos de idade.

No estágio inicial da doença, os sintomas externos são caracterizados pela cor amarelo-ouro das folhas basais, que começam na ponta e avançam em direção à ráquis, tornando-se necrosadas e quebram-se na base. No estágio mais avançado, a copa apresenta-se com um aspecto amarelo-ouro, com exceção de um tufo central de folhas verdes, as quais se dobram, secam e as plantas morrem (Ferreira et al., 1998).

A coloração avermelhada do anel deve-se a distúrbios metabólicos produzidos pela atividade dos nematóides, elevando o teor de gás carbônico no interior dos tecidos e, como conseqüência, alterando os complexos enzimáticos, como o dos glucosídeos, dando origem aos pigmentos antociânicos (Tihohod, 1993). Os danos causados pelos nematóides nos vasos xilemáticos induzem ao aparecimento de tiloses, que é o crescimento irregular das células do parênquima para dentro do xilema, causando uma oclusão vascular. A oclusão vascular em monocotiledôneas é irreversível, uma vez que não existem tecidos de câmbio para reparar, assim as plantas de coqueiro, portadoras da doença, morrem após alguns meses (Giblin-Davis, 2001). Uma pequena quantidade de nematóides é suficiente para o completo estabelecimento da doença (Griffith, 1968). Em coqueiros, os sintomas são observados 28 dias após a inoculação, com o pico populacional de nematóides ocorrendo 42 dias após (Goberdhan, 1964).

Este trabalho teve como objetivo conhecer como o nematóide $B$. cocophilus tende a se distribuir no interior das plantas de coqueiros em estágios avançados da doença, visando a contribuir para um melhor entendimento sobre os níveis populacionais do nematóide na planta.

\section{MATERIAL E MÉTODOS}

\section{Coleta do Material}

As amostras foram obtidas de plantas de coqueiro em estágio avançado da doença, com idade entre três e cinco anos, provenientes de uma propriedade localizada no município de São Miguel dos Milagres, distante $93 \mathrm{~km}$ da capital do Estado de Alagoas.

As amostras foram retiradas das seguintes partes da planta: raízes, estipe, palmito, pecíolos, ráquis e folíolos. As amostras de raízes foram retiradas junto à base da estipe e entre um e três metros de distância da planta, a profundidades de até $15 \mathrm{~cm}$. Como a densidade radicular na camada superficial diminui à medida que se afasta da planta, o número de nematóides nas amostras de raízes retiradas entre um e três metros de distância foi determinado em conjunto. Além dessas, utilizaram-se como amostras excrementos de $R$. palmarum obtidos em túneis abertos por larvas desse inseto.

Todo o material coletado foi levado para o Laboratório de Ecologia e Comportamento de Insetos (LECOM) da Universidade Federal de Alagoas, onde foram preparados. Para retirar resíduos de solo, as amostras de raízes foram lavadas em água corrente. Todas as partes vegetais foram cortadas em pequenos pedaços para facilitar a trituração durante o processamento. Apenas as amostras de folíolos, por serem provenientes de um material mais leve, foram compostas de $30 \mathrm{~g}$; as demais foram constituídas de $50 \mathrm{~g}$. Após a pesagem, as amostras foram colocadas em sacos de plástico e mantidas refrigeradas entre 3 e $5{ }^{\circ} \mathrm{C}$ até o processamento.

\section{Processamento das Amostras}

O processamento foi realizado no laboratório de fitopatologia da Unidade Acadêmica Centro de Ciências Agrárias da Universidade Federal de Alagoas. Os nematóides foram extraídos de acordo com a metodologia proposta por Hussey \& Barker (1973), mediante trituração de partes vegetais em liquidificador. Em seguida, os nematóides foram separados dos resíduos vegetais pela técnica proposta por Coolen e D'Herde (1972), utilizando-se de centrifugação.

As amostras foram colocadas em um liquidificador com $100 \mathrm{~mL}$ de água destilada e trituradas por $30 \mathrm{seg}$. Após a trituração, todo o material proveniente foi colocado em uma peneira granulométrica de 60 mesh, sobreposta a outra de 400 mesh. Com o auxílio de uma ducha, o material foi lavado na peneira de 60 mesh, que em seguida era retirada. Com a ajuda de uma pisseta, coletava-se o material que ficava retido na peneira de 400 mesh. Este era então colocado em tubos de plástico, que ficavam em um suporte de madeira. Cada tubo de plástico era pesado, e seu conteúdo completado com água até $72 \mathrm{~g}$. Em seguida, os tubos eram levados para centrifugação. Os tubos permaneciam na centrífuga por 4 minutos e $30 \mathrm{~s}$ a uma velocidade de $1.700 \mathrm{rpm}$. Cada vez que os tubos de plástico eram retirados da centrifuga, transferia-se a parte líquida para um becker, completava-se novamente sua massa com sacarose até $75 \mathrm{~g}$, e os tubos eram novamente centrifugados por 1 min e $30 \mathrm{~s}$. Novamente, a parte líquida era transferida para um becker, completados com solução de sacarose até $78 \mathrm{~g}$ e submetidos a uma terceira centrifugação, a $1.700 \mathrm{rpm}$, durante $1 \mathrm{~min}$. Mais uma vez, o sobrenadante era colocado em um becker e levado para a peneira de 400 mesh. Finalmente, o material era lavado com uma ducha de água e, com uma pisseta, efetuava-se a transferência do material para um 
recipiente de vidro. Para a adequada conservação da amostra, ao final do processamento, adicionava-se TAF ( $5 \%$ de trietanolamina, $5 \%$ de álcool, $75 \%$ de água e $15 \%$ de formol), completando o volume para $20 \mathrm{~mL}$.

\section{Estimativa do Número de B. cocophilus}

Com o auxílio de uma proveta, foram determinados quantos $\mathrm{mL}$ existiam em cada amostra. A homogeneização foi realizada soprando-se o líquido com o auxílio de uma pipeta. A estimativa do número de $B$. cocophilus em cada amostra foi realizada com o auxílio de um microscópio binocular Leica, modelo CME, com aumento de 100X e de um contador de células Kacil, modelo CCS-01. Foram utilizadas duas lâminas de Peter, cada uma contendo 1,0 $\mathrm{mL}$ de material. De posse das duas leituras, foi determinada uma estimativa para cada amostra através da regra de três simples. Dessa forma, foi obtido um número aproximado de nematóides presentes em cada amostra. Após cada contagem, as lâminas eram lavadas em água corrente para evitar contaminação.

\section{RESULTADOS E DISCUSSÃO}

Raiz - Os resultados deste trabalho indicaram que 95,8\% das amostras de raízes coletadas na base da estipe estavam contaminadas com B. cocophilus, das quais, 91,7\% continham até 200 nematóides. No entanto, houve uma amostra em que se encontraram 10.408 nematóides. O número médio de nematóides foi de 519,0 $\pm 430,09$. Apenas $23,8 \%$ das amostras de raízes coletadas entre um e três metros de distância da estipe continham nematóides. A média foi de 5,1 $\pm 2,78$ nematóides, e a quantidade máxima não ultrapassou a 55 nematóides $/ 50 \mathrm{~g}$ (Tabela 1 ).

Griffith \& Koshy (1990) constataram que, embora as raízes possam ser infectadas artificialmente, isso não é o modo normal do início da doença no campo, e que os nematóides não persistem no solo em número suficiente para que exista uma chance de infecção. Esses mesmos autores concluíram que, se uma fonte persistente de inóculo estiver presente, como pedaços de tronco de coqueiro enterrado, os quais podem permanecer frescos por duas semanas ou se uma alta população de B. cocophilus $\left(10^{4}\right.$ nematóides $/ \mathrm{cm}^{3}$ ) for adicionada ao solo, os nematóides podem penetrar na planta através das raízes senescentes e migrar para as partes superiores do tronco, produzindo os sintomas característicos da doença.

Os resultados deste trabalho também se assemelham aos de Kastelein (1987), que afirmou ser muito baixo, ou mesmo ausente, o número de nematóides encontrados nas raízes dos coqueiros doentes.

Schuiline \& Dinther (1981) relataram que, em plantações de coqueiro e dendê, não se detectou a presença do nematóide nas raízes de plantas doentes. Neste trabalho, constatou-se que, nas amostras de raízes coletadas junto à base da estipe de coqueiros doentes, o número de nematóides foi muito superior ao encontrado em raízes situadas entre um e três metros de distância da planta. Essa constatação permite concluir que, à medida que se afasta da planta doente, a possibilidade de se encontrar nematóides na raiz diminui, de forma que as chances de transmissão da doença através desse meio são muito pequenas. Por outro lado, Warwick \& Bezerra (1992) concluíram que o nematóide pode ser transmitido de uma planta contaminada para uma sadia através do contato das raízes.

Estipe e Palmito - No material vegetal coletado da estipe das plantas doentes, observou-se que todas as amostras estavam contaminadas, independentemente de terem sido retiradas do interior do anel-vermelho ou da área não-avermelhada. $\mathrm{Na}$ área interna do anel-vermelho o número máximo foi de 336.420 , e o mínimo, de 49.509 nematóides/50 g. A média de nematóides recuperados foi de $56.365,6 \pm 11.020,16$ nematóides $/ 50 \mathrm{~g}$. O número máximo de nematóides encontrados nas amostras oriundas da região não-avermelhada foi de 81.752 , e o mínimo foi de 3.504. A média foi de 56.464,0 $\pm 1.938,67$ nematóides $/ 50$ g. A média de nematóides na região avermelhada foi muito superior à encontrada na região não- avermelhada. Vale ressaltar que a média de nematóides na área aparentemente sadia da estipe da planta foi consideravelmente superior às encontradas nas demais regiões da planta doente (Tabela 1). Em várias amostras da estipe e do palmito, encontraram-se grandes números de ovos do nematóide.

Griffith \& Koshy (1990) encontraram entre 5.000 e 10.000 nematóides/g de tecido da região do anel-vermelho de plantas de coqueiro, enquanto uma região similar de plantas de dendê abrigava menos que 500 nematóides/g de tecido. Esses autores observaram que, como os nematóides não colonizam tão rapidamente o dendê como o fazem nas plantas de coqueiro, este morre após três meses de infecção por B. cocophilus, enquanto no dendê esse processo pode durar de três a quatro anos. Outra diferença é que, no dendê, a maioria dos nematóides é encontrada do lado de fora da zona avermelhada.

Das amostras coletadas da parte avermelhada do palmito, incluindo a região de crescimento da planta, $100 \%$ estavam contaminadas, enquanto $54,6 \%$ das amostras retiradas da região não-avermelhada, do mesmo material, apresentaram contaminação. O número máximo de nematóides recuperados foi de 6.893, e o mínimo, de 1.495. A média foi de 1.147,6 6 296,18 nematóides $/ 50 \mathrm{~g}$. Nas amostras coletadas da região nãoavermelhada, o número máximo de nematóides foi de 160 , e o mínimo, de 39 nematóides, sendo que a média foi de 28,7 $\pm 9,64$ nematóides $/ 50 \mathrm{~g}$ (Tabela 1 ).

Os resultados obtidos são semelhantes aos de vários autores, os quais relataram que, na região do palmito, onde o tecido é mais tenro, é possível encontrar o nematóide, tanto nas áreas avermelhadas quanto nas áreas aparentemente sadias (Nowell, 1919; Blair, 1970).

A causa para que os nematóides se concentrem, principalmente na estreita região do anel dos tecidos necrosados da estipe, nunca foi satisfatoriamente explicada (Griffith \& Koshy 1990). Nowell (1923) não encontrou nenhum fator anatômico ou fisiológico das plantas que pudesse explicar isso. Por outro lado, Martyn (1953) encontrou nematóides no interior das células de tecidos brancos, aparentemente sadios, até cerca de $1 \mathrm{~cm}$ para o lado externo e até $2,5 \mathrm{~cm}$ do lado interno do anel-vermelho. Dentro da região do anel, os nematóides foram encontrados nos tecidos 
inter e intracelulares. Martyn (1953) também expressou o ponto de vista de que o limite externo da zona vermelha do anel era determinado pelos tecidos mais duros da parte periférica da estipe e que o limite interno era determinado através da aeração e suprimento de água na planta. No entanto, parecem existir outros fatores que limitam a ocorrência e a atividade dos nematóides nas regiões exterior e interior do anel. A característica mais destacada de todos os tecidos invadidos por $B$. cocophilus é a presença de espaços intercelulares relativamente grandes, e a ausência desses espaços pode determinar o limite exterior do anel (Griffith \& Koshy, 1990).

Pecíolo, Ráquis e Folíolos - Das amostras provenientes do pecíolo, próximo à bainha da folha, $23,1 \%$ estavam contaminadas por $B$. cocophilus, sendo que o número máximo foi de 87 nematóides. A média foi de 14,1 1 8,69 nematóides $/ 50 \mathrm{~g}$. Nenhuma das amostras obtidas dos tecidos da ráquis e dos folíolos estava contaminada (Tabela 1).

Schuiline \& Dinther (1981) não detectaram a presença do nematóide nos pecíolos das folhas mais velhas do dendê e descartaram a possibilidade de transmissão da doença por ocasião da despalma. No entanto, esses autores encontraram alta concentração de nematóides (20 a 8.400/g de tecido) nas regiões necrosadas do pecíolo do coqueiro. Mais adiante, Kastelein (1987) também afirmou que um grande número de nematóides pode abrigar-se nos pecíolos das folhas mais velhas de coqueiro.

Os resultados deste trabalho revelaram que os nematóides, ainda que em pequena quantidade, podem ser encontrados nos tecidos do pecíolo. Portanto, práticas profiláticas, visando a desinfectar o facão utilizado, por ocasião da colheita e despalma do coqueiro, devem ser realizadas com a finalidade de eliminar a transmissão da doença.

Excrementos em Túneis Larvais de $R$. palmarum - Ao analisar as amostras de excrementos em túneis larvais removidos do palmito, observou-se que $100 \%$ estavam contaminadas, com o máximo de 938 e o mínimo de 126 nematóides. A média foi de $329,9 \pm 74,42$ nematóides/50 g. Das amostras de excrementos de túneis larvais removidos da base da estipe, apenas 31,3\% estavam contaminadas, com o máximo de 41 nematóides. A média foi de $12,88 \pm 3,46$ nematóides $/ 50 \mathrm{~g}$ (Tabela 1 ). Observou-se ainda que, nas amostras provenientes do palmito, encontrou-se uma grande quantidade de ovos do nematóide.

Referências sobre a população de B. cocophilus em excrementos de túneis larvais são muito escassas. Apenas a de Hagley (1963), que observou os nematóides distribuídos ao longo das cavidades de alimentação de R. palmarum. Hagley (1963) relatou ainda que, nos excrementos das galerias abertas pelas larvas na base do pecíolo e no palmito, podem ser encontrados, em média, 100 e 20 nematóides/g, respectivamente. Neste trabalho, não se examinaram excrementos provenientes do pecíolo, mas, em 50 gramas de excrementos do palmito, encontraram-se números próximos aos encontrados por Hagley (1963).

Em excrementos obtidos da zona do anel-vermelho e das suas partes, interna e externa, Hagley (1963) encontrou médias de 56; 45 e 52 nematóides/g, respectivamente. Neste trabalho, como os túneis eram muito irregulares, não foi possível precisar em que zona da região do anel as amostras foram coletadas. No entanto, existe uma tendência de a população de nematóide ser mais alta nos excrementos de túneis larvais da região apical do coqueiro, o que confere maior chance de serem transportados para outras plantas, aderidos ao corpo do seu principal vetor, os adultos de Rhynchophorus palmarum.

TABELA 1- Percentuais de amostras contaminadas com B. cocophilus em várias partes da planta e excrementos de túneis larvais de coqueiros portadores da doença anel- vermelho e média de nematóides recuperados.

\begin{tabular}{|c|c|c|c|c|c|}
\hline Material vegetal & $\mathbf{n}$ & $\begin{array}{c}\text { Amostras } \\
\text { contaminadas }\end{array}$ & $\begin{array}{c}\text { Número } \\
\text { Máx. }\end{array}$ & $\begin{array}{c}\text { Número } \\
\text { Min. }\end{array}$ & Média \pm EP \\
\hline Raiz da base da estipe & 24 & $23(95,8 \%)$ & 10.408 & 0 & $519,0 \pm 430,09$ \\
\hline Raiz distante 1 a $3 \mathrm{~m}$ da base da estipe & 21 & $5(23,8 \%)$ & 55 & 0 & $5,1 \pm 2,78$ \\
\hline Tecidos do interior do anel-vermelho da estipe & 39 & $39(100 \%)$ & 336.420 & 49.509 & $56.365,6 \pm 11.020,16$ \\
\hline Tecido da área não-avermelhada da estipe & 47 & $47(100 \%)$ & 81.752 & 3.504 & $5.464,0 \pm 1.938,67$ \\
\hline Tecido da área avermelhada do palmito & 36 & $36(100 \%)$ & 6.893 & 1.495 & $1.147,6 \pm 296,18$ \\
\hline Tecido da área não-avermelhada do palmito & 22 & $12(54,6 \%)$ & 160 & 39 & $28,7 \pm 9,64$ \\
\hline Base do pecíolo & 13 & $3(23,1 \%)$ & 87 & 0 & $14,1 \pm 8,69$ \\
\hline Ráquis & 11 & $0(0 \%)$ & 0 & 0 & ------- \\
\hline Folíolos & 55 & $0(0 \%)$ & 0 & 0 & -------- \\
\hline Excrementos de túneis larvais da base da estipe & 10 & $10(100 \%)$ & 938 & 126 & $329,9 \pm 74,42$ \\
\hline Excrementos de túneis larvais do palmito & 16 & $7(43,8 \%)$ & 41 & 0 & $12,8 \pm 3,46$ \\
\hline
\end{tabular}




\section{CONCLUSÕES}

1-Mais de 95\% das amostras de raízes coletadas na base da estipe de uma planta com anel- vermelho apresentam-se contaminadas com B. cocophilus, e à medida que se afasta da base da planta essa percentagem diminui para menos de $24 \%$.

2-A média de nematóides nas áreas, aparentemente sadias da estipe da planta, é consideravelmente superior às encontradas nas demais regiões da planta doente. $100 \%$ das amostras da parte avermelhada da estipe e do palmito, incluindo a região de crescimento da planta, estavam contaminadas por $B$. cocophilus.

3-Os nematóides podem ser encontrados nos tecidos do pecíolo. Portanto, práticas profiláticas de assepsia devem ser realizadas com a finalidade de eliminar a possibilidade de transmissão da doença por ocasião da colheita dos frutos.

4-A população de nematóide é mais alta nos excrementos de túneis larvais das regiões apicais do coqueiro, o que confere maior chance de serem transportados para outras plantas, aderidos ao corpo do seu principal vetor, os adultos de $R$. palmarum.

\section{AGRADECIMENTOS}

Ao Presidente da Associação dos Produtores de Coco de Alagoas (PROCOCO), Eurico Uchoa, pelo apoio ao desenvolvimento deste trabalho. À Fundação de Amparo à Pesquisa do Estado de Alagoas (FAPEAL), ao Banco do Nordeste do Brasil (BNB), pela concessão de bolsa e financiamento da pesquisa, e aos revisores anônimos, pelas sugestões na versão prévia do manuscrito.

\section{REFERÊNCIAS}

ARAÚJO, J.C.A. O anel-vermelho do dendê. Manaus: EMBRAPA, 1990.21p. (Circular Técnica)

BLAIR, G.P. Studies on red ring disease of coconut palm. Oléagineux, Paris, p.19-22. 1970.

BRATHWAITE, C.W.; SIDDIQI, M.R. Description of Rhadinaphelenchus cocophilus. In: C.I.H. Description of plantparasitic nematodes. Albans: Commonwealth Institute of Helmintology, 1975. 4p.

CHINCHILA, C.M. The red ring little leaf syndrome in oil palm and coconut palm. ASD Oil Palm Papers, Costa Rica, n. 1, p. 117. 1991.

COOLEN, W.A.; D'HERDE, C.J. A method for the quantitative extraction of nematodes from plant tissue. Ghent: Nematology and Entomology Research Station, 1972.77p.
FERREIRA, J.M.S.; WARWICK, D.R.N.; SIQUEIRA L.A. (eds.) A cultura do coqueiro no Brasil. 2.ed. Brasília: EMBRAPA/ CPATC, 1998.292 p.

FRANCO, E. Estudo sobre o anel-vermelho do coqueiro. Aracajú: Inspetoria de Defesa Fitossanitária, 1964. 264 p. (Publicação, 6)

GIBLIN-DAVIS, R.M. The red ring nematode and its vetores. Tallahassee: Florida Department of Agriculture and Consumer Services. Division of Plant Industry 1990. (Circular, 181).

GIBLIN-DAVIS, R.M. Insects of borers. In: HOWARD, F. W.; MOORE, D.; GIBLIN-DAVIS, R.M.; ABAD, R.G. Insects on palms. Wallingford-Oxon: CABI Publishing, 2001.414p.

GRIFFITH, R. The relationship between the red ring nematode and the palm weevil. Journal Agricultural Society Trinidad and Tobago, Wageningen, v.68, p. 342-356. 1968.

GRIFFITH, R.; KOSHY, P.K. Nematode parasites of coconut and other palms. In LUC, M., SIKORA, R.A.; BRIDGE, J. (Ed.), Plant parasitic nematodes in subtropical and tropical agriculture. Wallingford: CAB International, 1900. p.363-386.

GOBERDHAN, B. Observations on coconut palms artificially infected by the nematode Rhadinaphelenchus cocophilus (Cobb, 1919) Goodey, 1960. Journal of Helminthology., Wallingford, v.38, p.25-30. 1964.

HAGLEY, E.A.C. The role of the palm weevil, Rhynchophorus palmarum, as a vector of red ring disease of coconuts. I. Results of preliminary investigations. Journal of Economic Entomology, Lanham, v.56, n. 3, p. 375-380. 1963.

HUSSEYM R.S.; BARKER, K.R.A. Comparison of methods for collecting inocula of Meloidogyne spp. Including a new technique. Plant Disease Reporter, Washington, v.57, n.12, p.1025-1028. 1973.

KASTELEIN, P. Observations on red ring disease of coconut palm in Surinam. Surinaamse Landbouw, Paramibo, v.33, p.4053. 1987.

MARTYN, E. Red ring disease of coconuts in Trinidad and Tobago. Tropical Agriculture, Trinidad, v.30, p. 43-53. 1953.

NOWELL, W. The red ring or "root" disease of coconut palms. West Indian Bulletin, Barbados, v.17, n. 4, p.189-202. 1919.

NOWELL, W. Disease of crop plants of the Lesser Antilles. London: The West Indian Committee, 1923. 383p.

SÁNCHEZ, P.A.; CERDA, H. El complejo Rhynchophorus palmarum (L) (Coleoptera: Curculionidae) - Bursaphelenchus cocophilus (Cobb) (Tylenchida: Aphelenchoididae), en palmeras. Boletin de Entomologia Venezolana, Macaray, v.8, p.1-18, 1993. 
SCHUILING, M.; VAN DINTHER, M.B. Red ring disease in the Paricatuba oil palm estate, Brasil. Zeistschrift fuer Angewandte Entomologie, Hamburgy, p.154-169, 1981.

THURSTON, H. Red ring disease of coconut. In: THURSTON, H. Tropical plant disease. St Paul: American Phytopatholology Society, 1984. p.161-164.

TIHOHOD, D. Nematologia agrícola aplicada. Jaboticabal: FUNEP, 1993.372 p.
WARWICK, D.R.N.; BEZERRA, A.P.T. Possible root transmission of the red ring nematode (Rhadinaphelenchus cocophilus) to coconut palms. Plant Disease, St Paul, v.76, p. 809-811. 1992.

WARWICK, D.R.N.; LEAL, E.C. Principais doenças letais. p.5162. In: FERREIRA, J.M.S. (Ed.). Coco fitossanidade. Brasília: EMBRAPA, 2003. 106p. 